\title{
\$sciendo
}

DOI 10.2478/afepuc-2021-0003

(C) 2022 Author(s). This is an open access article licensed under the Creative Commons

Attribution-NonCommercial-NoDerivatives 4.0 International

(https://creativecommons.org/licenses/by-nc-nd/4.0/)

\section{PERCEIVED ETIOLOGY OF ANTI-SOCIAL BEHAVIOR AMONG PLAYERS AND SPECTATORS OF SELECTED FOOTBALL CLUBS IN NIGERIA (PEABFC)}

\section{Samson Olusola Babatunde}

Department of Human Kinetics and Health Education, Faculty of Education University of Lagos, Nigeria

\begin{abstract}
Summary: Anti-social behavior at football contest is a well-recognized issue. Due to this fact, associations and government have devised variety of interventions and strategy characterized by high tension and tempo among players and spectators which usually generate disorderliness of varying intensify. This study focuses on investigation of etiological factors of anti-social behaviors among players and spectators of football clubs in Nigeria during matches, with a view to coming up with coherent strategies for its enervation. Self-development questionnaire tagged perceived etiology of antisocial behavior among football players and spectators of selected football clubs (SPEABFC) was used for data collection, with reliability value of 0.85 . Two thousand seven hundred (2700) out of three thousand (3000) copies of questionnaire administered were retrieved and coded for analysis with adoption of percentages and chi-square $\mathrm{x}^{2}$ tool at 0.05 level at significant. The study copiously found that poor officiating, winning at all costs, conduct of coach and alcohol consumption are significant in causing anti-social behavior among players and spectators. Consequently, it is re-concluded among others that known troublemakers should be disallowed from entering the game venue, sale of alcohol be restricted to a place far from game site. The outcome is highly significant in view of the fact it might be helpful to scientifically develop appropriate strategies to control sale of drugs and alcohol at game site. The study is greatly insightful to sensitizes the management of football competitions to look inward more effective methods capable of making soccer context anti-behavior free. A adage says prevention is better than cure, the research is highly informative to authorities concerned with organization of football competitions map out preventive measures to unethical attitude by players, spectators as well fans for better attendance at game site which is likely to translate into making more profit for the organizers. An adequate provision for police and other security agents will go a long way to reduce anti-social behavior. We are now in the world of business geared towards profitability, any competition occasioned by riot and chaos is likely to negate this objective as attendance may reduce thereby drastically cutting the expected profit. The promoters of competition will be abreast this fact and develop remedies to counter it ahead at planning stage. The erring players should be sanctioned accordingly. The use of credible and
\end{abstract}


competent officials with records of integrity and credibility will in part promote sanity during the matches.

Keywords: Etiology, footballers, spectators, competition, anti-social behavior, football clubs

\section{Introduction}

Sports all over the world have been recognized as an important instrument for integration, peace and togetherness. There is no doubt that sports are among tools employed for peace nationally and internationally (Babatunde, 2004). Sulainan (2012) stated that the only means by which people unite throughout the universe is through sports. No matter one's tribe, culture, religion, social background, sports remains only festival and accommodated throughout the whole world. The paradox to this position is that many of football matches according to Omotayo (2008) and Babatunde (2003) are often ended abruptly due to anti-social behavior demonstrated by players and spectators in protest of poor officiating and other related vices.

Anti-social behavior at football matches is a well-recognized issue which has prompted police, football associations and governments to develop numerous interventions and strategies to prevent and respond to such behavior. Babatunde (2000) and Sulaiman (2012) affirmed that anti-social behaviors do not originate form a vacuum or mass during sports competitions, being more pronounced in football contests, but due to the volatile nature of the games. Babalola and Oyeniyi (2003) indicted that more often than not, there are causative factors behind anti-social behavior during sports competition. Babatunde (2000) remarked that empirical observations clearly revealed that lack of sportsmanship spirit often ignites unethical attitude on the part of athletes, coaches, spectators, as well as supporters.

Babatunde and Oyeniyi (2003) reported that the ripple effect of antisocial behavior is violence which irrefutably negates the spirit of sports and its objectives of which promotion of peace, unity and character building are among. According to Babatunde (2000) Babatunde (2004), Babalola and Oyeniyi (2003), sports supposedly contributes to character development and tremendously aids in the formation of ethical behavior. Contrarily in recent time, according to Oyeniyi (2001) one begins to wonder however, after viewing the contemporary sports scene, if these ingredients are somewhat antiquated. Owolabi (1992) pointed out that antisocial behavior during sports like football, basketball and lots required aggression which may 
eventually turn to violence in terms of destruction of valuable properties abruptly disruption of game, loss of lives and sustaining of injuries of varying severity.

Football game beyond doubt represents most popular game embraced by large number of people either as fans or spectators worldwide. Babatunde (2002), Oyeniyi (2001) and Babatunde (2003) elucidated that football game attracts the attention of both young and old worldwide. The relevance and popularity of football game cannot be over emphasized or underscored, judging from the fact that the game pulls high patronage from different segments of people as spectators, loyalists or supporters due to various underlying reasons such image making for clubs, state and nations. The economic values of the game to beneficiaries and anyone that has anything to do with the game, like betting which is now a legalized business is enormous (Babatunde 2005). All these according to Sulaiman (2012) may partly aggravate winning at all cost syndrome. Babatunde (2000) and Oyeniyi (2001) pointed out that winning at all costs and other related un- sportsmanship are among factors that may engender violence at sports contest.

Poor officiating being a strong issue that engenders anti-social behavior during football matches, as in the case where officials deliberately fail to adhere to rules and regulations of the game. Babatunde (2000), Babatunde (2004) and Sulaiman (2012) observed that many officials at football matches usually over project themselves by showing off which may direct the crown towards the officiating rather than towards contest. Oyeniyi (2001) is the same vein, indicated that incompetence on the part of officials could lead to bad officiating where officials are not up-to date with rules and regulations of sports being officiated thereby, leading to poor officiating that may irritated fans to trigger violence.

Consumption of alcohol is a known part of the experience of watching major national and international football events for fans and supporters in many parts of the world. According to Cooperation (2018), there is a long -standing relationship between international football and the alcohol beverages. Although there are restrictions of the use of alcohol at sports competition sites would casual observations reveals that brewery companies such as Heinekens, Guinness and lots have been official sponsors of champion leagues. Corporation, (2018) reported that Budweiser has been one of the main sponsors of FIFA world cup. The fact of this is that" he who pays the piper dictates the turn" measuring that the sponsors has moral and legal backing to display and sell their products which is alcohol at the game sites to recovered or revamp money expended on the sponsorship of the contests. 


\section{Hypotheses}

1. Poor officiating would not be a significant etiology of anti-social behavior among football players and spectators of related football players clubs in Nigeria.

2. Winning at all costs would not be a significant etiology of anti-social behavior among players and spectators of selected football clubs in Nigeria.

3. Conduct of coach at football competition site would not be a significant etiology of antisocial behavior at players and spectators of selected football clubs in Nigeria.

4. Alcohol consumption by footballers and spectators during football game would not be a significant etiology of anti-social behavior in selected football clubs in Nigeria.

\section{Alternative Hypotheses}

1. Poor officiating would be a significant etiology of anti-social behavior among football players and spectators of football clubs in Nigeria.

2. Winning at all costs would be significant etiology of anti-social behavior among football plyers and spectators in Nigeria.

3. Conduct of coach at football competition site would be a significant etiology of anti-social behavior among football players and spectators in Nigeria.

4. Alcohol consumption by football players and spectators would not be a significant etiology during football game during football game in selected football clubs in Nigeria.

\section{Method}

The research was carried out to delineate the etiology of anti-social behavior during football contests among the footballers and spectators of selected clubs in Nigeria with a view to mapping out scientific strategies by which such ugly behavior can be averted or attenuated to the barest minimal.

The instrument of the study was a self- developed questionnaire tagged Perceived etiology of anti-social behavior among football players and spectators of selected football clubs in Nigeria (PEABFC). The questionnaire is patterned after Likert scaling of Strongly Agreed $(\mathrm{SA})=4$ points, Agreed $(\mathrm{A})=3$ points Disagreed $(\mathrm{D})=2$ points and Strongly Disagreed $(\mathrm{SD})$ $=1$ points. The instrument was subjected to test-retest reliability with the value of 0.85 and a concomitant content validity arising from expert screening.

Fifty (50) football clubs and their spectators were used for the study. The clubs comprised premier league (Nigeria $1^{\text {st }}$ league) national league (Nigeria $2^{\text {nd }}$ league) division 
$1\left(3^{\text {rd }}\right.$ league) and Nigeria division 2 (Nigeria division 2). Three thousand $(3,000)$ questionnaire forms were administrated to players, referees, coaches and spectators during football matches with the help of trained research assistants. Five (5) research assistants with one assigned to ten (10) clubs during the administration of the instrument. Out of three thousand $(3,000)$ copies of questionnaire forms administrated two thousand seven hundred $(2,700)$ correctly completed and returned which represents $90 \%$ return rate were coded for analysis descriptive statistics of percent acted and chi-square $\left(\mathrm{X}^{2}\right)$ influential statistics were applied for the data analysis at 0.05 level of significance.

\section{Data Analysis and Discussion}

Table 1

Chi-square table of poor officiating

\begin{tabular}{|c|c|c|c|c|l|}
\hline Responses & Frequencies & $\begin{array}{c}\text { Frequencies } \\
\mathbf{\%}\end{array}$ & $\mathbf{X}^{\mathbf{2}}$ & $\begin{array}{c}\text { Agreement } \\
\text { Disagreement }\end{array}$ & Remarks \\
\hline S.A & 800 & 29.629 & 416.1 & 74.073 & \\
A & 1,200 & 44.444 & & 25.927 & Significant \\
D & 315 & 11.667 & & $100 \%$ & \\
Total & 2,700 & 100 & & & \\
\hline
\end{tabular}

Chi Square Vaue $X^{2}=416.1 ;$ df 3; $P=0.05$; Table Value: 7.815; Hypothesis: Significant

Table 1 above provides cursory analysis of chi-square value on poor officiating as an etiology of anti-social behavior among football players and spectators of the clubs selected for the study. From the table it is vivid that the obtained chi-square $\mathrm{X}^{2}$ value is significantly greater than the table value. This result logically depicts that the hypothesis which started that poor officiating would be an etiology of anti-social behavior among football players and spectators is rejected. This outcome without doubt corroborates the findings of Babatunde (2000) that poor officiating in terms of partiality and non- adherence to rules and regulations of the game by the official forms a major causative factor of unruly behavior among players and spectators.

\section{Table 2}

Chi-square $X^{2}$ table of winning at all costs as an etiology anti-social behavior during football matches

\begin{tabular}{|l|c|c|c|c|l|}
\hline Responses & Frequencies & $\begin{array}{c}\text { Frequencies } \\
\%\end{array}$ & $\mathbf{X}^{\mathbf{2}}$ & $\begin{array}{c}\text { Agreement } \\
\text { Disagreement }\end{array}$ & Remarks \\
\hline S.A & 650 & 24.074 & 255.45 & 70.37 & Significant \\
A & 1,250 & 46.296 & & 29.63 & \\
D & 590 & 21.852 & & & \\
Total & 210 & 77.78 & & & \\
& 2,700 & 100 & & $100 \%$ & \\
\hline
\end{tabular}

Chi Square Value $X^{2}=255.45 ; d f=3 ; P=0.05$; Table Value: 7.815; Hypothesis: Significant 
The Table 2 concentrates on the winning at all costs as an etiology of anti-social behavior among players and spectators. Babatunde (2000) observed that players who want to win at all costs do not always observe rules of the game, talk less of having regards for their opponents. The obtained chi-square $\left(\mathrm{X}^{2}\right)$ value as provided in table 2 is substantially bigger than the table value which justifies that the hypothesis that winning at all costs would not be the etiology of unethical behavior among players and spectators is refuted. Babalola and Oyeniyi (2003) unequivocally submitted that when players pursue winning at all costs, such player always disregard rules and regulations governing the game, thereby precipitating avoidable adverse behavior. Babatunde (2000) remarked that all over the world football game remains a sensitive enterprise that can generate friction particularly, if the rules are violated by the players or officials.

Sulaiman (2012), Oyeniyi (2001) and Babatunde (2000) found that winning at all costs make players not to display needed regards for the opponents on the field as stipulated in the rules of the game, which eventually degenerates to anti-social behavior. Sulaiman (2012) said that play to win at all costs may lead a player to cheat in order to reach his or her goal. It was further the mentioned that athletic point to their coaches as having a heavy influence on their decisions to win at all costs.

Table 3

Chi-square $\left(X^{2}\right)$ table of conduct of coach as an etiology of anti-social behavior among players and spectators

\begin{tabular}{|c|c|c|c|c|l|}
\hline Responses & Frequencies & $\begin{array}{c}\text { Frequencies } \\
\boldsymbol{\%}\end{array}$ & $\mathbf{X}^{\mathbf{2}}$ & $\begin{array}{c}\text { Agreement } \\
\text { Disagreement }\end{array}$ & Remarks \\
\hline S.A & 750 & 27.778 & 356.64 & 77.778 & Significant \\
A & 1,350 & 50.000 & & 22.222 & \\
D & 420 & 15.556 & & & \\
Total & 180 & 6.666 & & $100 \%$ & \\
& 2,700 & $100 \%$ & & & \\
\hline
\end{tabular}

Chi Square $X^{2}$ Value $=356.64 ; d f=3 ; P=0.05$; Table Value: 7.815; Hypothesis: Significant

Table 3 gives vivid information of conduct of coach as a factor responsible for antisocial behavior of football players and spectators during football contests. Like leader, like follower, Babatunde (2000) elucidated that the remote and immediate conduct of coaches is often instrumental to undesirable behavior demonstrated, especially by the players. Empirical observations such as Sulaiman (2012), Omotayo (2008), Babalola and Oyeniyi (2003) reported that the attitude of players good is related to training and support received from their coaches. Judging from the statistical information provided in the table 3, the alternative hypothesis is accepted while null hypothesis is rejected. 
Omotayo (2008) reported that coach is always accountable for the competent and noncompetent of players on the field of play. Babalola and Oyeniyi (2003) elicited that bad conduct of coaches or games masters at competitions can lead to hooliganism. There are occasions where coaches actually and overly instrumental to unruly behavior of athletes or players by their negative dispositions. Babatunde (2000) exposed that adverse comments of coaches may spur unethical behaviors among players as well as spectators. Many of the players according Sulaiman (2012) dwell on the negative comments of the coaches to manifest undesirable behavior on the field of play.

\section{Table 4}

Chi-square $\left(X^{2}\right)$ of alcohol consumption as an etiology of anti-social behavior among football players and spectators

\begin{tabular}{|l|c|c|c|c|l|}
\hline Responses & Frequencies & $\begin{array}{c}\text { Frequencies } \\
\mathbf{\%}\end{array}$ & $\mathbf{X}^{\mathbf{2}}$ & $\begin{array}{c}\text { Agreement } \\
\text { Disagreement }\end{array}$ & Remarks \\
\hline S.A & 730 & 27.037 & 309.69 & 81.481 & Significant \\
A & 1,470 & 54.444 & & & \\
D & 261 & 9.667 & & 18.519 & \\
Total & 239 & 8.852 & & $100 \%$ & \\
Chi-square $\left(X^{2}\right)=309.69: d f=3 ; P=0.05 ;$ Table Value: 7.815; Hypothesis: Significant
\end{tabular}

Alcohol is a common feature at national and international football events due to the fact that some of the events may have been sponsored by one beverage or the other. Although there are restrictions on alcohol consumption or display at football events observations confirm that due to issue of sponsorship by alcohol producers of sports events, alcohol is allowed at sports venue. Table 4 provides a glance at vivid empirical analysis 1 of anti-social behavior among footballers and spectators due to alcohol.

The calculate chi-square $x^{2}$ value in The Table 4 is statistically greater than table value. Therefore, the null hypothesis which stated that alcohol consumption would not be an etiology of unruly behavior among football players and spectators is rejected, while the alternative hypothesis is accepted. This shows that alcohol or any hard drug consumption is a strong variable aggravating anti-social behavior among players and spectators during matches. Babalola and Oyeniyi (2003), Oyeniyi (2001) and Babatunde (2000) attested to the fact that the use of hard drugs and alcohol by players and spectators prior time the close to or during competition could induce hooliganism. This is due to the fact that drugs and alcohol when used by players and spectators do affect their level of judgement and behavior, which may lead to players and other stakeholders to play dangerously and act negatively which is capable of 
causing injury and disorderliness. Babatunde (2004) reiterated that alcohol is often associated with crime, poverty and other social problems, including hooliganism and other related disorderliness. Corporation (2018) remarked that alcohol is recognized as a factor that may contribute to anti-social and violent behavior at football matches although the casual relationship remains unclear. Bushman \& Cooper (1999) indicated that studies have described a link between alcohol consumption and display of aggression in some individuals. To support the link of alcohol and football matches, Eberhardt et al (2016) reported that almost half of surveyed fans at the 2014 World Cup reported having consumed alcohol prior to entering a stadium. In further support of legal availability of alcohol at football match venue, Elgan et al (2018) exposed that designated areas as created typically condoned off public spaces with specific regulations and security arrangements for fans, spectators to congregate, watch matches on giant screens and enjoy other forms of entertainment. In these spaces, alcohol sales and purchases are typically permitted via official vending points.

\section{Conclusions}

The thrust of the research is on the etiology of anti-social behavior of football players and spectators during competitions. The spectators comprise general crowd, supporters as well as fans. The outcomes of the research work analytically conclude the following:

1. Poor officiating is a critical factor for anti-social behavior among players and spectators

2. Winning at all costs is also found as a significant issue that generates disorderliness among football players and spectators during football matches.

3. Conduct and disposition of coaches are found to be significant causative factor of antisocial behaviors among players and spectators

4. The study identified alcohol among other predisposing factors of ugly behavior of players and spectators as a strewing indismissible root cause of unethical behavior during football matches.

\section{Recommendations}

There is no doubt that football game is an important and popular sports nationally and internationally. This is why the game attracts high magnitude of crowd across the world. In contrast to the inherent values of the game, the matches sometimes are characterized by antisocial behaviors due to variety of reasons. The study systematically isolated some of the factors behind the unethical behaviors during football matches, with a view to figure out scientific but 
programmatic strategies by which such identified disorderliness can be arrested. Therefore, the following recommendations are proffered:

1. Officials to be in involved in officiating should be those with records of personal integrity, credibility and proficiency in professionalism. Any unprofessional conduct observed among the officials when officiating must be treated or dealt with in concomitant with rules and regulations as provided by body governing the game. Officials should as a matter of ethics attempt to be as unobtrusive as possible and of not becoming a dominant force on the field.

2. Education of players, fans as well as spectators on essence of sportsmanship would go a long way in reducing winning at all costs attitude of these stakeholders .This can be promoted by organizing seminars for all the stakeholders and via various media. Organizing spectators' education through various media and seminars, focusing on importance of desirable conduct at game site by the bodies concerned with organization of football contests will substantially help to reduce undesirable behavior among spectators and fans.

3. Players who demonstrate any unethical behavior on the field during the context should be disciplined as law provided. The law for misbehavior of any player during match must be strictly enforced by the governing body of the game.

4. The governing bodies of football games as a matter of policy must enforce restrictions of the sales of alcohol at the game sites by applying conferment of the sales and consumption of alcohol to a given place a bit far away from the field of play since the sale may not be totally prohibited or curtailed since the management of such breweries are often the sponsors of the competitions.

\section{References}

1. BABALOLA J. F. \& P. O. OYENIYI, 2003. Cursory hooliganism during collegiate spent in Nigeria: West African journal of physical \& health education. 7: 58-63, Ibadan, department of human kinetics and health education, university of Ibadan.

2. BABATUNDE, S. O., 2000. Panacea to sport violence at collegiate level proceeding of the $1^{\text {st }} 1$ CHAPER-SP, African regional conference 109-112.

3. BABATUNDE, S. O., 2005. Socio-cultural perspectives of sports participation. Ilonri journal of health, physical education and relation department of physical and health education. 4:43-50. University of Ilorin. 
4. BABATUNDE, S. O., 2000. Alcohol and alcoholism in ogundele, B.O (Ed) problems in health education. Ibadan; Department of human kinetics and health education, university of Ibadan 115-133.

5. BUSHMAN B. \& H.M. Cooper, 1990. Effects of alcohol on human aggression: an integrative research review, psychological bulletin. 07(3): 341-54 Corporation (2018) https: //www.rand.org/ pubs/research- reports/ rr2777.html.Cording, S(2018) NO alcohol ( advertising) No world cup:- FIFA'S influence on alcohol regulation.

6. CORPORATION, 2018.https//www.rand.org/research_reports/RR2777.htmml.

7. DURBEEJ N., T. H. ELGAN \& C. D. JALLING GRRIPENBERY, 2017. Alcohol Intoxication at Sweedish Football matches Football matches: A study using piological sampling to assess blood alcohol concentration level among spectators, plos one 129110: e0188284.Eberhardt KA vinnemeier, C.D Health Risks Related to Mass Gathering/Sports Events and Implications for the Summer Olympic Games in Rio de Janeiro in 2016. Travel Medicine and infectious Disease. 14(3):212-20.

8. EBERHARDT, K. A., C. D. Vinnemeier, J. Dehnerdt, T. Rolling, R. Steeffen \& J. P. Cramer, 2016.Travelerst the FIFA Word Cup 2014 in Brazil:

9. ROLLIN T., R. STEFFEN \& J. P. CREAMER, 2001B. Traveler to the FIFA world cup 2014 in Brazil health risks related to mass gathering sports events and implications for the summer Olympic games in Rio de Janairo in 2016.

10. ELGEN, T. H., H. D. N DURBEEJI \& J. HOLDER GRIPENBERG, 2018. Over serving and Allowed Entry of Obviously Alcohol Intoxicated Spectators at Sporting Events'. Alcohol; Clinical and Experimental Research. 42(2): 444-52. ESPN. 2018, UEFA Lifts Champions league and EuropA League Alcohol Ban' 26 June 2018;

11. OWOLABI, E. O, 1992. Reducing sports costs through effective control of violence in sports. In Adesanya, O. A Onifade A., Obayemi, W, Morakinyo E.O. Akaindetire I.O. (Eds) Journal of Nigeria Academic of Sports Administration. I(1x2).

12. SULAIMAN, O. F., 2012. Anti-Social Behaviors Causation Among Football Players and Spectators. An unpublished M.sc dissertation.

13. OMOTAYO, O. O., 2008. Selected Nigerian soccer players opinion on appropriation of identified solution to soccer game hooliganism and violence. Nigerian journal of sports management. 2(39-44) Lagos: Nigeria society for sports management \% department of physical and health education, Lagos state university Ojo. 
14. OYENIYI, P. O., 2001. Sourcing funds for effective administration of school sports in Nigeria. In Y. AWOSIKA, J. F. BABALOLA, J. O. OSIKI \& B. O. EMUNEMU (eds.) Topical Issue in Education: Papers In Honour of Prof. C.O. Udoh, Ibadan: CodatPublications, pp. $11-18$. 